\title{
Anaerobic and aerobic metabolism of glycogen- accumulating organisms selected with propionate as the sole carbon source
}

\author{
Adrian Oehmen,† Raymond J. Zeng,‡ Aaron M. Saunders,§ \\ Linda L. Blackall, Jürg Keller and Zhiguo Yuan

\begin{abstract}
Advanced Wastewater Management Centre (AWMC), The University of Queensland, St Lucia,
\end{abstract} \\ Brisbane 4072, Australia
}

Correspondence

Zhiguo Yuan

zhiguo@awmc.uq.edu.au

Received 24 March 2005

Revised 4 April 2006

Accepted 5 May 2006

\begin{abstract}
In the microbial competition observed in enhanced biological phosphorus removal (EBPR) systems, an undesirable group of micro-organisms known as glycogen-accumulating organisms (GAOs) compete for carbon in the anaerobic period with the desired polyphosphate-accumulating organisms (PAOs). Some studies have suggested that a propionate carbon source provides PAOs with a competitive advantage over GAOs in EBPR systems; however, the metabolism of GAOs with this carbon source has not been previously investigated. In this study, GAOs were enriched in a laboratory-scale bioreactor with propionate as the sole carbon source, in an effort to better understand their biochemical processes. Based on comprehensive solid-, liquid- and gas-phase chemical analytical data from the bioreactor, a metabolic model was proposed for the metabolism of propionate by GAOs. The model adequately described the anaerobic stoichiometry observed through chemical analysis, and can be a valuable tool for further investigation of the competition between PAOs and GAOs, and for the optimization of the EBPR process. A group of Alphaproteobacteria dominated the biomass ( $96 \%$ of Bacteria) from this bioreactor, while postfluorescence in situ hybridization (FISH) chemical staining confirmed that these

Alphaproteobacteria produced poly- $\beta$-hydroxyalkanoates (PHAs) anaerobically and utilized them aerobically, demonstrating that they were putative GAOs. Some of the Alphaproteobacteria were related to Defluvicoccus vanus (16\% of Bacteria), but the specific identity of many could not be determined by FISH. Further investigation into the identity of other GAOs is necessary.
\end{abstract}

\section{INTRODUCTION}

Enhanced biological phosphorus removal (EBPR) is a widespread activated sludge process for the removal of phosphorus from wastewater. Sequential anaerobic and aerobic phases are employed for the enrichment of a group

†Present address: Lab. 505 - Departamento de Química, Faculdade de Ciências e Tecnologia, Universidade Nova de Lisboa (UNL), 2829-516 Caparica, Portugal.

$\ddagger$ Present address: Environment and Resources DTU, Bygningstorvet, bldg. 115, The Technical University of Denmark, DK - 2800 Lyngby, Denmark.

§Present address: Department of Microbial Ecology, Aarhus University, Ny Munkegade, 8000 Aarhus C, Denmark.

Abbreviations: acetyl-CoA*, activated acetyl-CoA; EBPR, enhanced biological phosphorus removal; FISH, fluorescence in situ hybridization; $\mathrm{GAO}$, glycogen-accumulating organism; PAO, polyphosphate-accumulating organism; $\mathrm{PHA}$, poly- $\beta$-hydroxyalkanoate; $\mathrm{PHB}$, poly- $\beta$-hydroxybutyrate; $\mathrm{PH} 2 \mathrm{MV}$, poly- $\beta$-hydroxy-2-methylvalerate; $\mathrm{PHV}$, poly- $\beta$ hydroxyvalerate; propionyl-CoA*, activated propionyl-CoA; SBR, sequencing batch reactor; TFO, tetrad-forming organism; TOGA, titration and off-gas analysis; VFA, volatile fatty acid. of bacteria known as polyphosphate-accumulating organisms (PAOs), which are primarily responsible for EBPR. Another group of bacteria, glycogen-accumulating organisms (GAOs), also proliferate in systems with sequential anaerobic and aerobic phases, competing with PAOs for the often limiting carbon substrates (Bond et al., 1998; Satoh et al., 1994; Thomas et al., 2003; Whang \& Park, 2002). Currently, there are no pure cultures of PAOs or GAOs (Seviour et al., 2003), so their biochemical transformations have been determined through chemical analyses of enriched laboratory-scale mixed EBPR microbial communities. Metabolic models have been proposed to describe the biochemical transformations occurring in PAOs consuming acetate (Smolders et al., 1994a, b, 1995) and propionate (Oehmen et al., 2005b) as the sole carbon source. Similarly, GAO enrichments consuming acetate have also been modelled (Filipe et al., 2001a; Zeng et al., 2002, 2003b). These metabolic models provide useful tools for optimization of EBPR and for research into the competition between PAOs and GAOs.

Under anaerobic conditions, both PAOs and GAOs can take up volatile fatty acids (VFAs) and convert them into 
intracellular poly- $\beta$-hydroxyalkanoates (PHAs). To obtain the energy for anaerobic VFA uptake, the metabolic models propose that PAOs hydrolyse intracellularly stored polyphosphate and glycogen, while GAOs hydrolyse only glycogen for this purpose, as they have no stored polyphosphate. Under aerobic conditions, PAOs and GAOs oxidize the intracellular PHA to grow and to replenish their stored glycogen. PAOs also use a portion of the energy generated from PHA oxidation for orthophosphate uptake and synthesis of intracellular polyphosphate. Since GAOs consume the limited VFAs in the anaerobic period without contributing to phosphorus removal, they are highly undesirable microorganisms in EBPR systems.

Culture-independent methods have been used to identify a $\mathrm{PAO}$, named 'Candidatus Accumulibacter phosphatis' (Accumulibacter), which is a member of the family Rhodocyclaceae within the Betaproteobacteria (Crocetti et al., 2000; Hesselmann et al., 1999). Fluorescence in situ hybridization (FISH) has shown Accumulibacter to be an abundant organism in laboratory-scale EBPR cultures with various carbon sources (Levantesi et al., 2002; Liu et al., 2001; Oehmen et al., 2004, 2005b; Onda et al., 2002; Pijuan et al., 2004; Zeng et al., 2003a). Accumulibacter has also been reported in full-scale EBPR systems (Saunders et al., 2003; Zilles et al., 2002). A similar approach has identified deeply branching members of the Gammaproteobacteria (Nielsen et al., 1999) as putative GAOs. These organisms have been called either 'Candidatus Competibacter phosphatis' (henceforth called Competibacter, Crocetti et al., 2002) or the GB lineage (Kong et al., 2002). Competibacter can consume acetate as the sole carbon source, but a recent study has shown that they take up propionate very slowly (Oehmen et al., 2005a), and thus tend to be out-competed by Accumulibacter (Oehmen et al., 2005a, 2006; Pijuan et al., 2004).

Tetrad-forming organisms (TFOs; also called 'G-bacteria') have been linked to the deterioration of EBPR in laboratoryscale systems. Using culture-independent methods, two distinct groups of TFOs have recently been identified as members of the Alphaproteobacteria and shown to be putative GAOs. One group are members of the order Sphingomonadales, and the other is related to the isolate Defluvicoccus vanus within the order Rhodospirillales. Both of these organisms could consume acetate as the sole carbon source (Beer et al., 2004; Wong et al., 2004), but the D. vanus-related organism has also been recently demonstrated to consume propionate (Meyer et al., 2006), unlike Competibacter.

This study investigated the metabolism of an enriched culture of Alphaproteobacteria TFOs that were fed with propionate as the sole carbon source and demonstrated the GAO phenotype. Anaerobic and aerobic biochemical transformations as well as maintenance processes are described in detail from experimental data, and a metabolic model describing propionate uptake by GAOs is proposed.

\section{METHODS}

Reactor setup and operation. An enrichment of GAOs was obtained through operation of a sequencing batch reactor (SBR) for a period of 5 months. The SBR had a working volume of 81 and was operated with $6 \mathrm{~h}$ cycles, beginning with a $130 \mathrm{~min}$ anaerobic period, followed by a $160 \mathrm{~min}$ aerobic period and a $70 \mathrm{~min}$ settle and decant period. Two litres of synthetic wastewater (Smolders et al., 1994b; Zeng et al., 2003b) with propionate as the sole carbon source were fed during the first $6 \mathrm{~min}$ of the anaerobic period in each cycle, resulting in a hydraulic retention time (HRT) of $24 \mathrm{~h}$. The sludge retention time (SRT) was approximately 8 days, with $250 \mathrm{ml}$ mixed liquor being wasted at the end of each aerobic period. The $\mathrm{pH}$ was maintained at $7 \cdot 0 \pm 0 \cdot 1$ during the anaerobic and aerobic phases using a one-way controller that dosed $0.5 \mathrm{M} \mathrm{HCl}$ when the $\mathrm{pH}$ was above the setpoint. The reactor was seeded with sludge from an SBR enriched for PAOs, as reported in Oehmen et al. (2005b), and maintained under identical operational conditions apart from a considerably reduced level of phosphate in the feed ( $2 \mathrm{mg} \mathrm{PO}_{4}-\mathrm{P}^{-1}$ instead of $53 \mathrm{mg} \mathrm{PO}_{4}-\mathrm{P}^{-1}$ ) to select for GAOs, where $\mathrm{PO}_{4}-\mathrm{P}$ is phosphate.

Cycle studies and batch experiments. The performance of the SBR was monitored through cycle studies in which samples were collected at various points throughout a cycle and chemically analysed. Propionate, PHA, glycogen, orthophosphate and ammonia were analysed (Oehmen et al., 2005b) every $10 \mathrm{~min}$ for the first $40 \mathrm{~min}$ of the anaerobic period, followed by $20 \mathrm{~min}$ intervals thereafter. In the subsequent aerobic phases, PHA, glycogen, orthophosphate and ammonia analyses were carried out every 20-30 min. Total suspended solids (TSS) and volatile suspended solids (VSS) samples were determined at the end of each aerobic period (APHA, AWWA \& WPCF, 1995).

Oxygen consumption and $\mathrm{CO}_{2}$ production during a cycle were determined via the titration and off-gas analysis (TOGA) sensor with $2 \mathrm{~h}$ anaerobic and $3 \mathrm{~h}$ aerobic phases (Pratt et al., 2003).

The anaerobic hydrogen ion production (or consumption) found in each test with the TOGA sensor is caused by two main factors. Propionic acid uptake by GAOs leads to the consumption of $\mathrm{H}^{+}$, and $\mathrm{CO}_{2}$ production has a $\mathrm{pH}$ effect through dissolving in the liquid and influencing the bicarbonate acid-base system. The total amount of hydrogen ions produced $\left(\mathrm{HP}_{\text {total }}\right)$ can be determined as:

$\mathrm{HP}_{\text {total }}=\frac{\text { propionate }_{\text {uptake }}}{3}+\frac{\left(\mathrm{CO}_{2 \text { produced }}-\mathrm{CO}_{\text {transfer }}\right)}{1+10^{\mathrm{pK}_{\mathrm{a}}-\mathrm{pH}_{\mathrm{op}}}}$

where the $\mathrm{CO}_{2}$ produced minus the $\mathrm{CO}_{2}$ transferred to the gas phase is equal to the $\mathrm{CO}_{2}$ dissolved in the liquid. The operational $\mathrm{pH}\left(\mathrm{pH}_{\mathrm{op}}\right)$ is maintained at $7 \cdot 0$ in these tests and the $\mathrm{pK}_{\mathrm{a}}$ is $6 \cdot 35$ for the bicarbonate acid-base buffering system. The anaerobic $\mathrm{CO}_{2}$ production can therefore be calculated as:

$$
\begin{aligned}
& \mathrm{CO}_{2 \text { produced }}=\left(1+10^{\mathrm{pK}_{\mathrm{a}}-\mathrm{pH}_{\mathrm{op}}}\right) \\
& \left(\mathrm{HP}_{\text {total }}-\frac{\text { propionate }}{\text { uptake }}+\frac{\mathrm{CO}_{2 \text { transfer }}}{3}+10^{\mathrm{pK}_{\mathrm{a}}-\mathrm{pH}_{\mathrm{op}}}\right.
\end{aligned}
$$

where the $\mathrm{CO}_{2}$ transfer and hydrogen ion production are measured through the TOGA sensor, and the propionate uptake is measured through off-line samples. The aerobic $\mathrm{CO}_{2}$ production was determined in a similar manner to anaerobic $\mathrm{CO}_{2}$ production, where the $\mathrm{HP}_{\text {total }}$ is influenced by ammonium uptake for biomass growth instead of 
propionate uptake:

$$
\begin{aligned}
& \mathrm{CO}_{2 \text { produced }}=\left(1+10^{\mathrm{pK}_{\mathrm{a}}-\mathrm{pH}_{\mathrm{op}}}\right) \times \\
& \left(\mathrm{HP}_{\text {total }}-\text { ammonium }_{\text {uptake }}+\frac{\mathrm{CO}_{2 \text { transfer }}}{1+10^{\mathrm{pK}_{\mathrm{a}}-\mathrm{pH}_{\mathrm{op}}}}\right)
\end{aligned}
$$

A more detailed description of the TOGA and the determination of $\mathrm{CO}_{2}$ production has been reported in the literature (Oehmen et al., 2005b; Pratt et al., 2003; Zeng et al., 2003b).

Determination of the anaerobic and aerobic maintenance coefficients. The rate of glycogen hydrolysis, PHA accumulation and $\mathrm{CO}_{2}$ production incurred by anaerobic maintenance was determined through an $8 \mathrm{~h}$ anaerobic batch test without propionate addition. The aerobic maintenance was found through extending the aerobic period to $9 \mathrm{~h}$ in one of the TOGA tests described above for the determination of oxygen uptake and $\mathrm{CO}_{2}$ production. All other operational procedures in the anaerobic and aerobic maintenance batch tests were identical to those described above.
Analytical procedures. Orthophosphate, ammonia, nitrate and nitrite were analysed using a QuikChem8000 (Lachat, WI) flow injection analyser (FIA). Propionic acid was measured by HPLC with an HPX-87H $300 \times 7 \cdot 8 \mathrm{~mm}$ Bio-Rad Aminex ion exclusion HPLC column operated at $65^{\circ} \mathrm{C}$. FIA and propionic acid samples were obtained through filtering mixed liquor from the SBR using $0 \cdot 22 \mu \mathrm{m}$ Millex GP syringe-driven filters. Total suspended solids (TSS) and volatile suspended solids (VSS) concentrations were determined in accordance with standard methods (APHA, AWWA \& WPCF et al., 1995). Glycogen and PHA analyses were performed as reported in Oehmen et al. (2005b). Elemental analysis of the enriched biomass was performed using $0.5 \mathrm{mg}$ lyophilized sludge in a Perkin-Elmer 240 Elemental Analyser. The carbon, hydrogen, oxygen and nitrogen measurements were used to determine the active biomass composition, after subtracting the PHA and glycogen components stored in the sludge.

FISH was carried out as detailed in Amann (1995), and a list of all oligonucleotide probes used during this study is shown in Table 1.

Table 1. Oligonucleotide probes used during this study

Helper probes are designated with an $\mathrm{H}$; competitor probes are designated with a c.

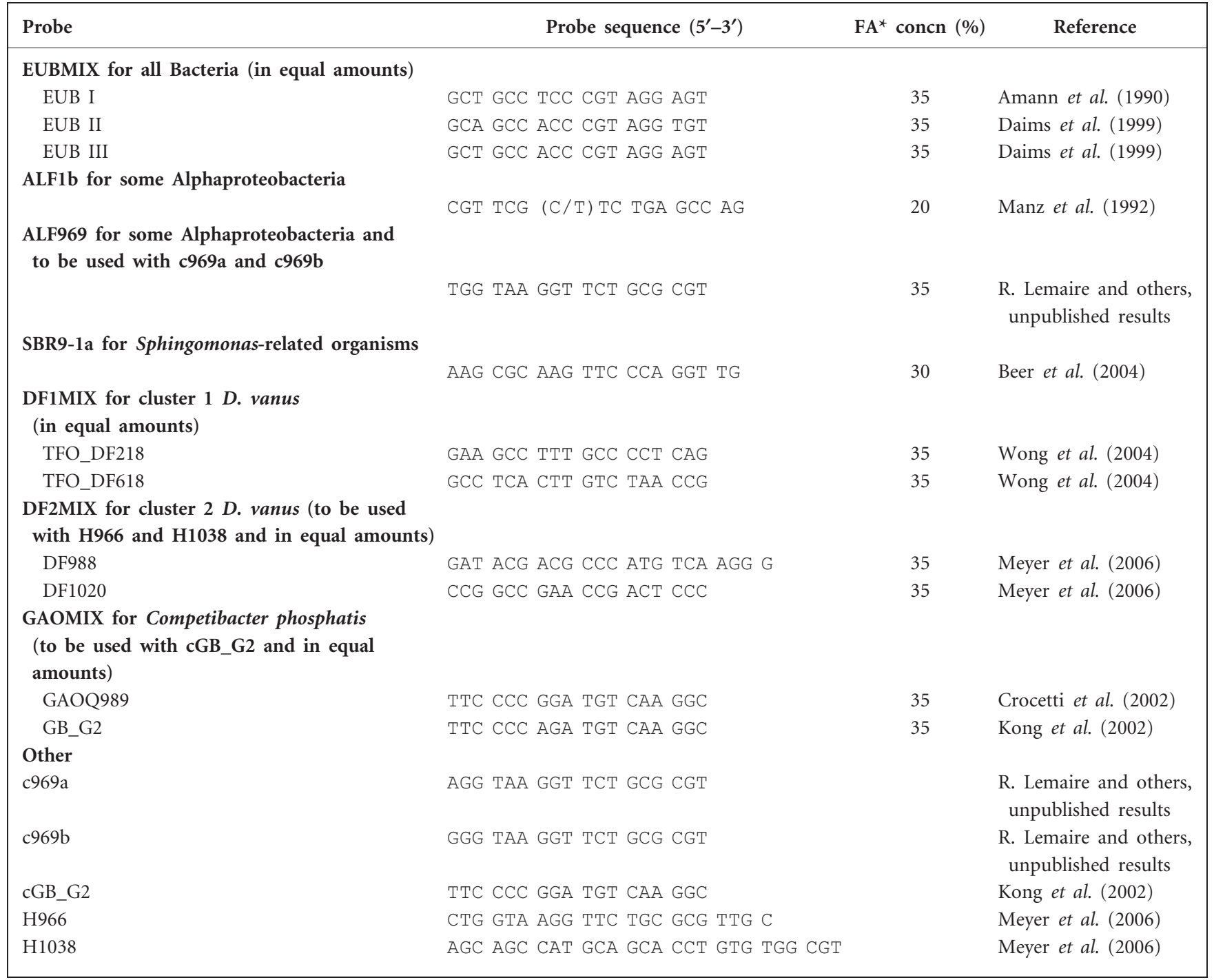

${ }^{\star} \mathrm{FA}$, formamide (used in FISH buffer). 
ALF1b (Manz et al., 1992) and ALF969 (R. Lemaire and others, unpublished results) probes were used for Alphaproteobacteria. ALF969 was modified from ALF968 (Neef, 1997) because Competibacter and Kouleothrix (a filamentous organism commonly found in activated sludge systems (Beer et al., 2002) are perfectly targeted by ALF968. Competitor probes targeting Competibacter and Kouleothrix were added without a fluorescent label to ensure the differentiation of these organisms from Alphaproteobacteria.

The probed biomass was examined using a Zeiss LSM510 Meta confocal laser scanning microscope. Quantification was done using previously reported image analysis techniques (Bouchez et al., 2000; Crocetti et al., 2002), in which the area of cells binding the specific probe is expressed as the mean percentage of the area of the entire bacterial community (EUBMIX, Table 1). The standard error of the mean (SEM) was calculated as the standard deviation of the area percentage divided by the square root of the number of images $(n=51)$. Post-FISH chemical staining was carried out as detailed by Crocetti et al. (2002) using Nile Blue to stain for PHA (Ostle \& Holt, 1982). Samples from the end of both the anaerobic and aerobic periods were stained to confirm intracellular PHA cycling.

\section{RESULTS AND DISCUSSION}

\section{SBR operation}

A cycle study of the SBR that illustrates the typical steadystate operation is shown in Fig. 1. The GAO phenotype is clearly displayed: VFA uptake, PHA accumulation and glycogen degradation under anaerobic conditions; and PHA oxidation and glycogen replenishment under aerobic conditions. There was no phosphorus release observed in the SBR after the first month of operation. Nitrification inhibition was achieved through addition of allyl- $N$ thiourea, and confirmed by the absence of $\mathrm{NO}_{\mathrm{x}}$ (below the detection limit) throughout the reactor operation. The primary fractions of PHA formed through propionate uptake were poly- $\beta$-hydroxyvalerate (PHV) and poly- $\beta$ hydroxy-2-methylvalerate (PH2MV). This differs from GAOs enriched with acetate, which produce primarily poly- $\beta$-hydroxybutyrate (PHB) and PHV (Filipe et al., 2001a; Zeng et al., 2003b).

\section{FISH and post-FISH chemical staining}

FISH quantification showed that $96 \%$ of all bacteria in the SBR (SEM $=1 \%)$ were Alphaproteobacteria (ALF969). The cells hybridizing the ALF969 probe also hybridized the ALF1b probe, confirming the specificity of the ALF969 probe. Morphologically, almost all of the Alphaproteobacteria were TFOs; other morphologies were only observed in very low abundance. Most of the Alphaproteobacteria observed using FISH (Fig. 2A) contained PHA at the end of the anaerobic period (Fig. 2B), and the PHA was mostly absent from the cells at the end of the aerobic phase (data not shown). The anaerobic-aerobic cycling of PHA in the Alphaproteobacteria cells combined with their abundance in the biomass strongly supports the hypothesis that they were putative GAOs.

Competibacter (GAOMIX, Table 1) and Sphingomonasrelated organisms (SBR9-1a) were not detected in the biomass. DF1MIX (Table 1) Defluvicoccus-related organisms accounted for $8 \%(\mathrm{SEM}=1 \%)$ of the Bacteria. DF2MIX (Table 1) Defluvicoccus-related organisms accounted for an additional $8 \%(\mathrm{SEM}=1 \%)$ of the Bacteria, and the cells that bound these probes were TFOs. The fact that the majority of Alphaproteobacteria in the biomass that cycled PHA did not bind the current probes for GAOs strongly suggests the presence of other GAOs, despite the similar morphology of these organisms to those described in the literature (Beer et al., 2004; Meyer et al., 2006; Wong et al., 2004). It may be that the probes from these publications do not target the diversity of the organisms within these already identified groups so that additional sequences are required in order to broaden the probe specificities; alternatively, another group of GAOs unrelated to Sphingomonas or D. vanus may exist.

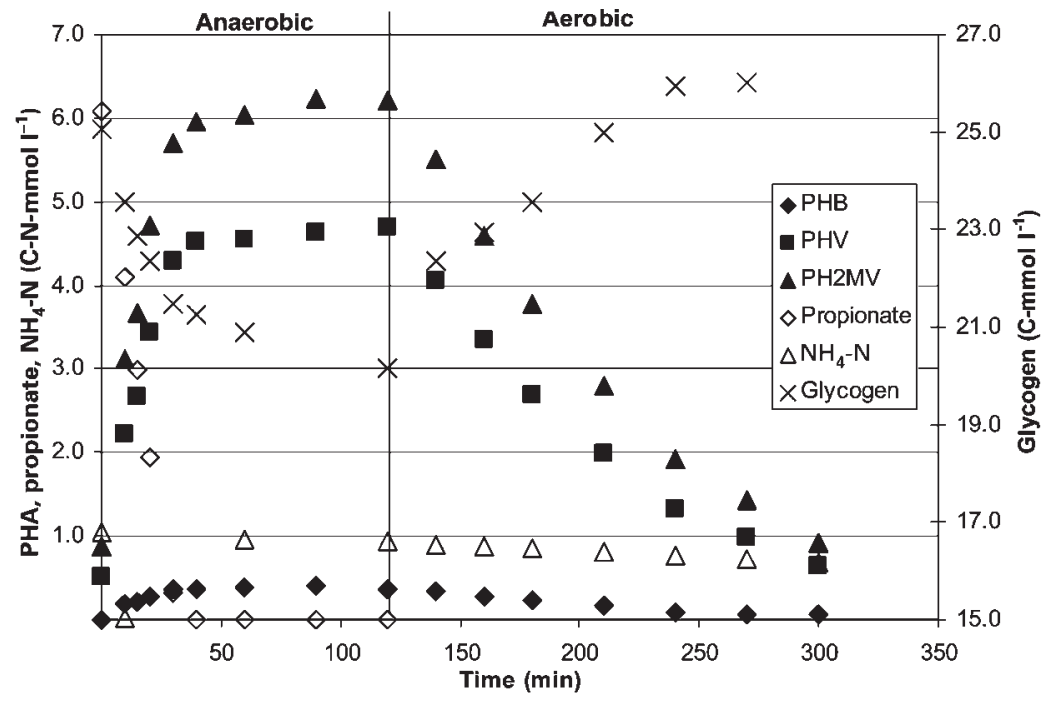

Fig. 1. Cycle study showing VFA, PHA, glycogen and ammonia transformations from a typical cycle in the SBR. The GAO phenotype of anaerobic VFA uptake, and anaerobic-aerobic cycling of PHA and glycogen is clearly displayed. 

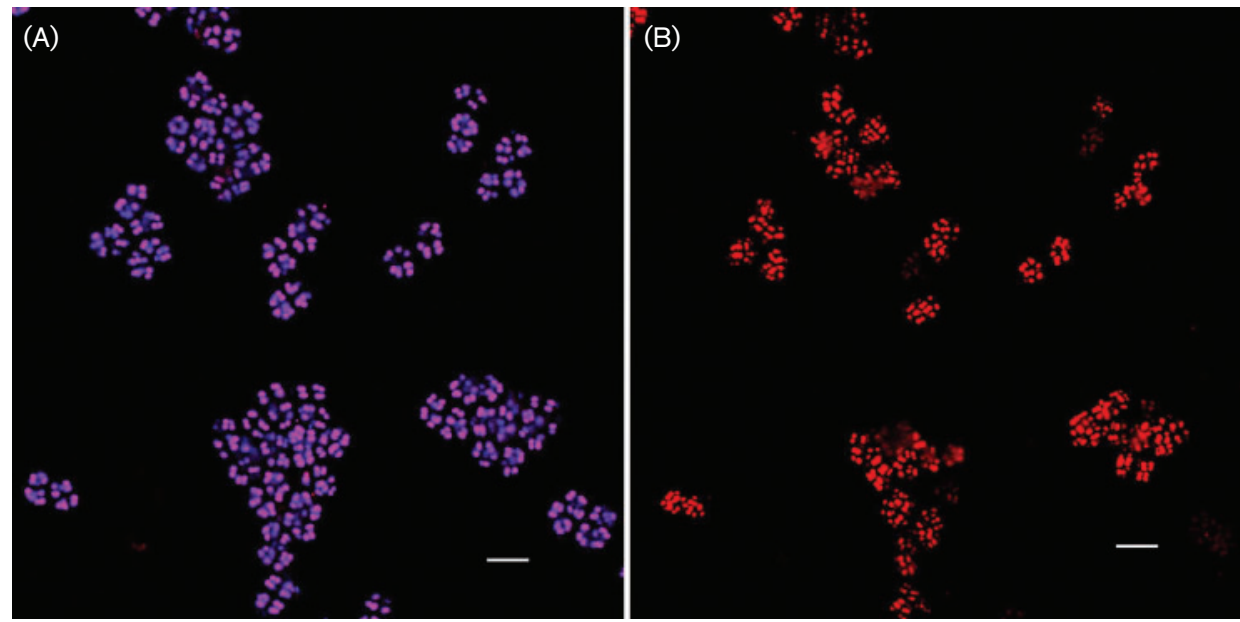

Fig. 2. Images of the same microscopic field of biomass taken from the end of the anaerobic period. (A) FISH showing Alphaproteobacteria (ALF969; magenta) and all other Bacteria (EUBMIX; blue), and (B) post-FISH staining with Nile Blue for PHA (red). PHA was not observed in biomass samples taken from the end of aerobic period (not shown). Thus, these Alphaproteobacteria cells are putative GAOs as anaerobic-aerobic cycling of PHA was observed. Bars, $10 \mu \mathrm{m}$.

\section{A metabolic model for propionate uptake by GAOs}

A metabolic model has been formulated as outlined below to describe the anaerobic metabolism of propionate by GAOs, and is presented schematically in Fig. 3. Propionate is taken up anaerobically by GAOs and converted to propionyl-CoA, using glycogen hydrolysis as the sole energy source. Glycogen glycolysis to pyruvate generates energy in the form of ATP, proceeding through what is hypothesized to be the Embden-Meyerhof (EM) pathway (Filipe et al., 2001a). A portion of the pyruvate is converted to acetyl-CoA and $\mathrm{CO}_{2}$, which produces reducing equivalents in the form of $\mathrm{NADH}_{2}$. The remainder of the pyruvate is converted to propionyl-CoA (consuming $\mathrm{NADH}_{2}$ in the process) such that the reduction-oxidation (redox) balance is maintained within the cells. Acetyl-CoA and propionyl-CoA are then reduced to form activated acetyl-CoA (acetyl-CoA ${ }^{\star}$ ) and activated propionyl-CoA (propionyl-CoA ${ }^{\star}$ ), the precursors of PHA. Assuming acetyl-CoA and propionyl-CoA are

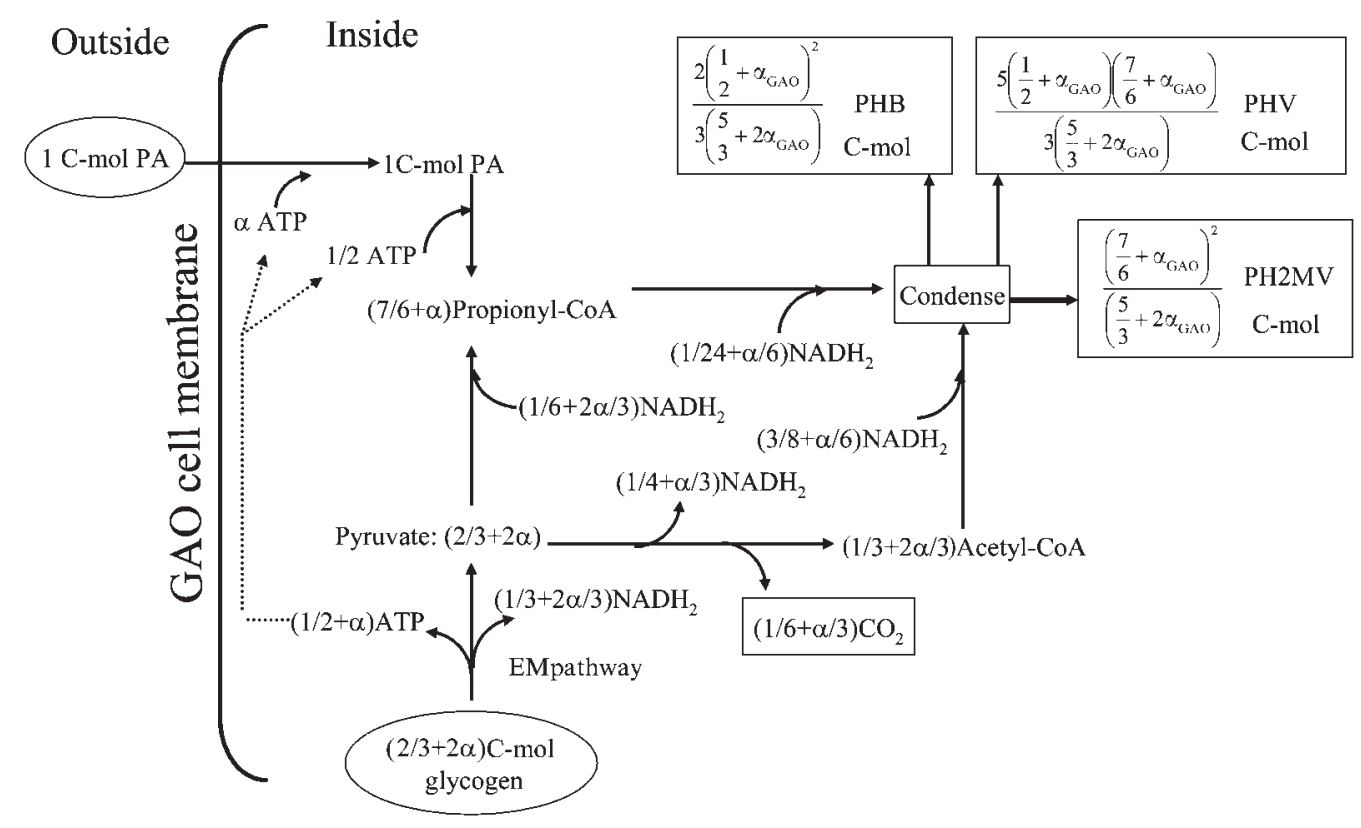

Fig. 3. Schematic of the proposed metabolism of propionate (PA) by GAOs, adapted from Zeng et al. (2003b), showing consumption and production of components. All parameters are presented on a C-mol basis. 
randomly condensed, the PHA composition is calculated based on the probability of these molecules combining together in a large pool of acetyl-CoA and propionyl-CoA (Filipe et al., 2001a). Selective condensation proposes that all of the acetyl-CoA will preferentially bind to propionylCoA to form PHV, while the the remainder of the propionyl-CoA molecules are condensed to $\mathrm{PH} 2 \mathrm{MV}$, resulting in no PHB production (Oehmen et al., 2005b). The experimental results are compared later to the model predictions for both random and selective condensation of acetyl-CoA and propionyl-CoA.

A model describing the aerobic processes of GAOs has been developed previously by Zeng et al. (2003b). This model may also be applied when propionate is the carbon source fed anaerobically. The change in carbon source only affects the fractions of acetyl-CoA and propionyl-CoA metabolized aerobically. These parameters may be obtained from the anaerobic model stoichiometry.

\section{GAO metabolic model reactions}

$\mathrm{r}_{1}$, propionate is taken up into the cell and converted to propionyl-CoA, where $\alpha_{\mathrm{GAO}}$ is defined as the energy required for transport of one carbon-mole (C-mol) of VFA across the cell membrane, which has been shown to be pH dependent (Filipe et al., 2001a; Smolders et al., 1994b):

- Propionate $-\left(1+3 \alpha_{\mathrm{GAO}}\right) \mathrm{ATP}+$ propionyl-CoA + $\mathrm{H}_{2} \mathrm{O}=0$

$\mathrm{r}_{2}$, glycogen is hydrolysed via the EM pathway (Gottschalk, 1986):

$$
- \text { Glycogen }-\mathrm{H}_{2} \mathrm{O}+2 \text { pyruvate }+3 \mathrm{ATP}+2 \mathrm{NADH}_{2}=0
$$

$r_{3}$, acetyl-CoA production from pyruvate through oxidative decarboxylation (Voet \& Voet, 1990):

- Pyruvate $+\mathrm{NADH}_{2}+\mathrm{CO}_{2}+$ acetyl-CoA $=0$

$\mathrm{r}_{4}$, propionyl-CoA production from pyruvate through the propionate-succinate pathway (Gottschalk, 1986):

- Pyruvate $-2 \mathrm{NADH}_{2}+$ propionyl- $\mathrm{CoA}+2 \mathrm{H}_{2} \mathrm{O}=0$

$\mathrm{r}_{5}$, activated acetyl-CoA (acetyl-CoA ${ }^{\star}$ ) production (Filipe et al., 2001a):

-Acetyl-CoA $-0 \cdot 5 \mathrm{NADH}_{2}+$ acetyl-CoA ${ }^{*}=0$

$\mathrm{r}_{6}$, activated propionyl-CoA (propionyl-CoA ${ }^{\star}$ ) production (Filipe et al., 2001a):

$$
\text { - Propionyl-CoA }-0 \cdot 5 \mathrm{NADH}_{2}+\text { propionyl-CoA }{ }^{*}=0
$$

The aforementioned internal reactions may be expressed in terms of the measurable parameters as shown below:

$\mathrm{r}_{\text {propionate }}=-\mathrm{r}_{1}$

$\mathrm{r}_{\text {glycogen }}=-\mathrm{r}_{2}$

$$
\begin{aligned}
& \mathrm{r}_{\mathrm{CO}_{2}}=\mathrm{r}_{3} \\
& \mathrm{r}_{\text {pyruvate }}=2 \mathrm{r}_{2}-\mathrm{r}_{3}-\mathrm{r}_{4} \\
& \mathrm{r}_{\text {acetyl-CoA }}=\mathrm{r}_{5} \\
& \mathrm{r}_{\text {propionyl-CoA }}=\mathrm{r}_{6} \\
& \mathrm{r}_{\mathrm{NADH}}=2 \mathrm{r}_{2}+\mathrm{r}_{3}-2 \mathrm{r}_{4}-0 \cdot 5 \mathrm{r}_{5}-0 \cdot 5 \mathrm{r}_{6} \\
& \mathrm{r}_{\mathrm{ATP}}=-\left(1+3 \alpha_{\mathrm{GAO}}\right) \mathrm{r}_{1}+3 \mathrm{r}_{2} \\
& \mathrm{r}_{\text {acetyl-CoA }}=\mathrm{r}_{3}-\mathrm{r}_{5} \\
& \mathrm{r}_{\text {propionyl-CoA }}=\mathrm{r}_{1}+\mathrm{r}_{4}-\mathrm{r}_{6} \\
& \mathrm{r}_{\mathrm{H}_{2} \mathrm{O}}=\mathrm{r}_{1}-\mathrm{r}_{2}+2 \mathrm{r}_{4}
\end{aligned}
$$

Assuming that there is no accumulation of energy, reducing power, acetyl-CoA, propionyl-CoA and pyruvate then $\mathrm{r}_{\mathrm{NADH}_{2}}=0, \mathrm{r}_{\mathrm{ATP}}=0, \mathrm{r}_{\text {acetyl-CoA }}=0, \mathrm{r}_{\text {propionyl-CoA }}=0$ and $r_{\text {pyruvate }}=0$. The internal and measurable reactions are then resolved with respect to propionate uptake, where the energy required for transport of $1 \mathrm{C}$-mol of propionate across the $\mathrm{GAO}$ cell membrane is defined as the parameter $\alpha_{\mathrm{GAO}}$ :

$$
\begin{aligned}
& r_{2}=\left(1 / 3+\alpha_{\mathrm{GAO}}\right) r_{1} \\
& r_{3}=\left(1 / 2+\alpha_{\mathrm{GAO}}\right) r_{1} \\
& r_{4}=\left(1 / 6+\alpha_{\mathrm{GAO}}\right) r_{1} \\
& r_{5}=\left(1 / 2+\alpha_{\mathrm{GAO}}\right) r_{1} \\
& r_{6}=\left(7 / 6+\alpha_{\mathrm{GAO}}\right) r_{1} \\
& r_{\text {propionate }}=-\mathrm{r}_{1} \\
& \mathrm{r}_{\text {glycogen }}=-\left(1 / 3+\alpha_{\mathrm{GAO}}\right) \mathrm{r}_{1} \\
& \mathrm{r}_{\mathrm{CO}}=\left(1 / 2+\alpha_{\mathrm{GAO}}\right) \mathrm{r}_{1} \\
& \mathrm{r}_{\mathrm{acetyl}-\mathrm{CoA}}=\left(1 / 2+\alpha_{\mathrm{GAO}}\right) \mathrm{r}_{1} \\
& \mathrm{r}_{\text {propionyl-CoA }}=\left(7 / 6+\alpha_{\mathrm{GAO}}\right) \mathrm{r}_{1} \\
& \mathrm{r}_{\mathrm{H}_{2} \mathrm{O}}=\left(1+\alpha_{\mathrm{GAO}}\right) \mathrm{r}_{1}
\end{aligned}
$$

Therefore, the following overall relationship can be obtained (mole basis):

$$
\begin{aligned}
& \text { - Propionate }-\left(\frac{1}{2}+\alpha_{\mathrm{GAO}}\right) \text { glycogen } \\
& +\left(1+\alpha_{\mathrm{GAO}}\right) \mathrm{H}_{2} \mathrm{O}+\left(\frac{1}{2}+\alpha_{\mathrm{GAO}}\right) \mathrm{CO}_{2}
\end{aligned}
$$




$$
\begin{aligned}
& +\left(\frac{1}{2}+\alpha_{\mathrm{GAO}}\right) \text { Acetyl-CoA }{ }^{*} \\
& +\left(\frac{7}{6}+\alpha_{\mathrm{GAO}}\right) \text { Propionyl-CoA }{ }^{*}=0
\end{aligned}
$$

Assuming that acetyl-CoA ${ }^{*}$ and propionyl-CoA ${ }^{\star}$ are randomly condensed as $\mathrm{PHB}, \mathrm{PHV}$ and $\mathrm{PH} 2 \mathrm{MV}$, as reported in Filipe et al., then the overall equation is shown below (C-mol basis):

$$
\begin{aligned}
& -\mathrm{CH}_{2} \mathrm{O}_{2 / 3}-\left(2 / 3+2 \alpha_{\mathrm{GAO}}\right) \mathrm{CH}_{10 / 6} \mathrm{O}_{5 / 6} \\
& +\left(1 / 3+\alpha_{\mathrm{GAO}} / 3\right) \mathrm{H}_{2} \mathrm{O} \\
& +\frac{2\left(0.5+\alpha_{\mathrm{GAO}}\right)^{2}}{3\left(5 / 3+2 \alpha_{\mathrm{GAO}}\right)} \mathrm{CH}_{1.5} \mathrm{O}_{0.5} \\
& +\frac{5\left(0.5+\alpha_{\mathrm{GAO}}\right)\left(7 / 6+\alpha_{\mathrm{GAO}}\right)}{3\left(5 / 3+2 \alpha_{\mathrm{GAO}}\right)} \mathrm{CH}_{1.6} \mathrm{O}_{0.4} \\
& +\frac{\left(7 / 6+\alpha_{\mathrm{GAO}}\right)^{2}}{\left(5 / 3+2 \alpha_{\mathrm{GAO}}\right)} \mathrm{CH}_{5 / 3} \mathrm{O}_{1 / 3}+\left(1 / 6+\alpha_{\mathrm{GAO}} / 3\right) \mathrm{CO}_{2}=0
\end{aligned}
$$

If selective condensation of acetyl-CoA ${ }^{*}$ and propionyl$\mathrm{CoA}^{\star}$ occurs as detailed in Oehmen et al. (2005b), then there is no $\mathrm{PHB}$ production, and the overall equation is adjusted to:

$$
\begin{aligned}
& -\mathrm{CH}_{2} \mathrm{O}_{2 / 3}-\left(2 / 3+2 \alpha_{\mathrm{GAO}}\right) \mathrm{CH}_{10 / 6} \mathrm{O}_{5 / 6} \\
& +\left(1 / 3+\alpha_{\mathrm{GAO}} / 3\right) \mathrm{H}_{2} \mathrm{O} \\
& +\left(5 / 6+5 / 3 \alpha_{\mathrm{GAO}}\right) \mathrm{CH}_{1.6} \mathrm{O}_{0.4}+2 / 3 \mathrm{CH}_{5 / 3} \mathrm{O}_{1 / 3} \\
& +\left(1 / 6+\alpha_{\mathrm{GAO}} / 3\right) \mathrm{CO}_{2}=0
\end{aligned}
$$

\section{Characterizing the anaerobic stoichiometry of propionate-enriched GAOs}

The anaerobic biochemical transformations found experimentally in this study are summarized in Table 2, and compared to the model predictions. Glycogen, PHA and VFA were analysed through off-line samples as described above. The anaerobic $\mathrm{CO}_{2}$ production was found through equation (2) using the $\mathrm{CO}_{2}$ transfer and hydrogen ion production data obtained through the TOGA sensor (shown in Fig. 4), in conjunction with the propionate uptake. From the experimental results shown in Table 2, a carbon recovery of $97 \cdot 8 \%$ was achieved through a carbon balance, while a redox balance yielded $99 \cdot 5 \%$ recovery. Both results support the accuracy of the experimental data and strongly suggest that all relevant compounds were measured in the experiments.

In Table 2, a close fit can be observed between the experimental data and the metabolic model based on random condensation of acetyl-CoA and propionyl-CoA. This suggests that the proposed model adequately describes the stoichiometry associated with propionate uptake by GAOs. In contrast to the findings for GAOs, the stoichiometry of PAOs fed with propionate has been found to correlate closely with the model based on selective condensation of acetyl-CoA and propionyl-CoA (Oehmen et al., 2005b). The reason for this observed difference in PHA formation between PAOs (selective) and GAOs (random) is unclear at present, but seems to indicate a slight, yet distinctive, difference between the metabolic pathways of these organisms.

The energy required for transport of $1 \mathrm{C}$-mol of propionate across the GAO cell membrane is defined as the parameter $\alpha_{\mathrm{GAO}}$, which is dependent on the ambient $\mathrm{pH}$ of the system (Filipe et al., 2001a; Smolders et al., 1994b). The model predictions in Table 2 represent the case when $\alpha_{\mathrm{GAO}}$ equals zero. Filipe et al. (2001a) estimated an $\alpha_{\mathrm{GAO}}$ of 0.06 at a $\mathrm{pH}$ of $7 \cdot 0$ for an acetate-enriched GAO culture. Further investigation into the estimation of the $\alpha_{\mathrm{GAO}}$ parameter for GAOs would be

\begin{tabular}{|c|c|c|c|c|c|c|}
\hline Model or experiment (reference) & Gly/VFA & $\mathrm{CO}_{2} / \mathrm{VFA}$ & PHB/VFA & PHV/VFA & PH2MV/VFA & PHA/VFA \\
\hline Model, random & $0 \cdot 67$ & $0 \cdot 17$ & $0 \cdot 10$ & $0 \cdot 58$ & $0 \cdot 82$ & $1 \cdot 50$ \\
\hline Experimental SD & $0 \cdot 03$ & $0 \cdot 03$ & $0 \cdot 01$ & $0 \cdot 03$ & $0 \cdot 03$ & $0 \cdot 05$ \\
\hline Propionate PAO model (Oehmen et al., 2005b) & $0 \cdot 33$ & $0 \cdot 11$ & 0 & $0 \cdot 56$ & $0 \cdot 67$ & $1 \cdot 22$ \\
\hline Acetate GAO model (Zeng et al., 2002) & $1 \cdot 12$ & $0 \cdot 27$ & $1 \cdot 36$ & $0 \cdot 46$ & $0 \cdot 04$ & $1 \cdot 86$ \\
\hline
\end{tabular}
beneficial in order to support the hypothesis that $\alpha_{\mathrm{GAO}}$ does indeed equal zero at a $\mathrm{pH}$ of $7 \cdot 0$, as suggested by this study.

\section{Aerobic stoichiometry}

The aerobic stoichiometry observed in this study is summarized in Table 3. The carbon balance closes to

Table 2. Anaerobic stoichiometry associated with propionate uptake by GAOs: model predictions and experimental results, in comparison with PAO and GAO studies from the literature

All units are $\mathrm{C}-\mathrm{mol} \mathrm{C}-\mathrm{mol}^{-1}$. Experimental results shown are the mean obtained from five separate cycle studies, except for $\mathrm{CO}_{2}$ production, which was obtained through averaging results from three TOGA tests. Results were calculated from the ratio of the carbon transformation rates during the period of propionate uptake. 


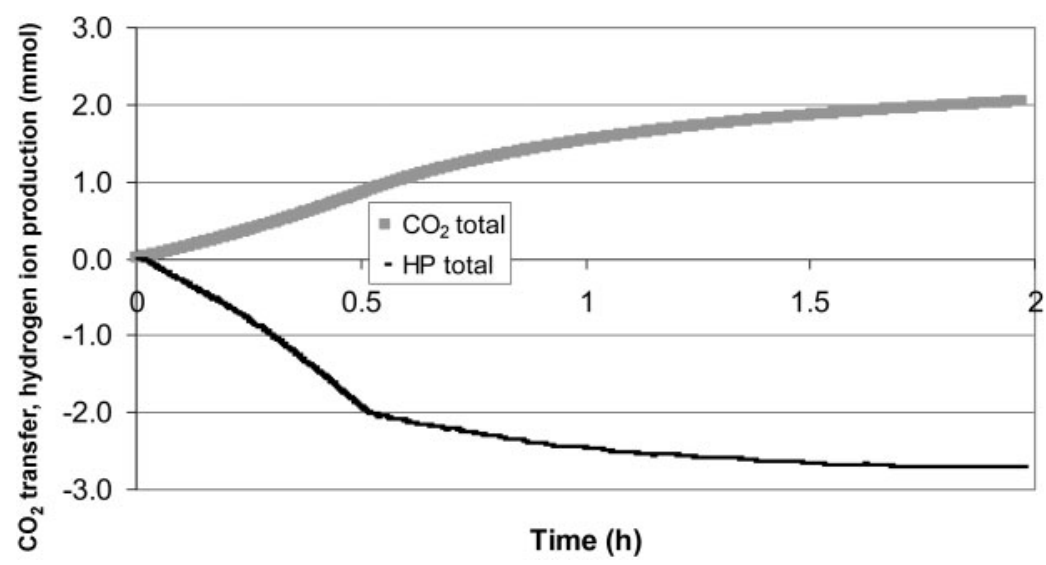

Fig. 4. Cumulative $\mathrm{CO}_{2}$ transfer and hydrogen ion production during an anaerobic period of the SBR, from which the anaerobic $\mathrm{CO}_{2}$ production was found to be $0.20 \mathrm{C}$ $\mathrm{mol} \mathrm{C}-\mathrm{mol}^{-1}$ of propionate uptake [equation (2)].

$99 \cdot 8 \%$, while a redox balance yields $93.3 \%$ recovery. Fig. 5 shows the oxygen uptake rate and $\mathrm{CO}_{2}$ transfer rate for a batch test of an extended aerobic cycle using the TOGA sensor. The total oxygen consumption shown in Table 3 was obtained through numerical integration of the oxygen uptake rate for a series of three aerobic periods. The aerobic $\mathrm{CO}_{2}$ production was calculated using equation (3) from the measured cumulative $\mathrm{CO}_{2}$ transfer and hydrogen ion production from the TOGA sensor, as well as the ammonia uptake obtained through off-line analysis and shown in Table 3.

Due to the absence of nitrification in the SBR, the ammonia uptake could be used to calculate the biomass growth through dividing the ammonia uptake by the nitrogen coefficient from the experimentally determined biomass composition $\left(\mathrm{CH}_{1 \cdot 89} \mathrm{O}_{0 \cdot 62} \mathrm{~N}_{0 \cdot 18}\right)$. The biomass growth was estimated to be $1.96 \mathrm{C}-\mathrm{mmol} \mathrm{l}^{-1}$ by this method (see Table 3). Biomass growth may also be estimated using the wastage of biomass per cycle, after taking into consideration the PHA and glycogen storage products in the sludge. Using this method, the biomass growth was estimated to be 1.94 $\mathrm{C}$-mmol ${ }^{-1}$. These estimations are within $2 \%$ of each other,

Table 3. Aerobic stoichiometry of carbon, nitrogen and oxygen transformations for GAOs enriched with propionate

All results obtained were the mean of experimental data from three separate TOGA tests. The anaerobic propionate consumption was $6 \cdot 1$ $\mathrm{C}-\mathrm{mmol} \mathrm{l}^{-1}$ and the biomass concentration was $65 \cdot 2 \mathrm{C}-\mathrm{mmol}^{-1}$ for these tests.

\begin{tabular}{|lcc|}
\hline Parameter & Aerobic stoichiometry & Units \\
\hline Glycogen production & $7 \cdot 56$ & $\mathrm{C}-\mathrm{mmol} \mathrm{l}^{-1}$ \\
PHB consumption & $0 \cdot 36$ & $\mathrm{C}-\mathrm{mmol} \mathrm{l}^{-1}$ \\
PHV consumption & $4 \cdot 42$ & $\mathrm{C}-\mathrm{mmol} \mathrm{l}^{-1}$ \\
PH2MV consumption & $5 \cdot 75$ & $\mathrm{C}-\mathrm{mmol} \mathrm{l}^{-1}$ \\
Ammonium consumption & $0 \cdot 36$ & $\mathrm{~N}-\mathrm{mmol} \mathrm{l}^{-1}$ \\
Biomass production & $1 \cdot 96$ & $\mathrm{C}-\mathrm{mmol} \mathrm{l}^{-1}$ \\
$\mathrm{O}_{2}$ consumption & $2 \cdot 64$ & $\mathrm{mmol} \mathrm{l}^{-1}$ \\
$\mathrm{CO}_{2}$ production & $1 \cdot 04$ & $\mathrm{C}-\mathrm{mmol} \mathrm{l}^{-1}$ \\
\hline
\end{tabular}

supporting the hypothesis that either method may be used to calculate the biomass growth, which has been suggested by Zeng et al. (2003b).

\section{Anaerobic and aerobic maintenance characterization}

It has been hypothesized that the sole energy source for anaerobic maintenance in GAOs is obtained through glycogen hydrolysis. An equation to describe the anaerobic maintenance process by GAOs has been proposed (Filipe et al., 2001a; Zeng et al., 2003b):

$$
\begin{aligned}
& - \text { Glycogen }+\frac{1}{6} \mathrm{PHB}+\frac{5}{12} \mathrm{PHV}+\frac{1}{4} \mathrm{PH} 2 \mathrm{MV} \\
& +\frac{1}{6} \mathrm{CO}_{2}+\frac{1}{2} \mathrm{ATP}=0
\end{aligned}
$$

In this study, the anaerobic batch test without VFA addition allowed the estimation of the specific anaerobic maintenance coefficient $\left(m^{\text {ATP }}\right)$ [in mol ATP (C-mol biomass) $)^{-1}$ $\mathrm{h}^{-1}$. The glycogen hydrolysis rate obtained from this batch test is shown in Fig. 6, and was found to be $7 \cdot 0 \times 10^{-3} \mathrm{C}$ mol (C-mol biomass $)^{-1} \mathrm{~h}^{-1}$. The corresponding $m^{\text {ATP }}$ value is therefore determined to be $3.5 \times 10^{-3}$ mol ATP (C-mol biomass) $)^{-1} \mathrm{~h}^{-1}$ from equation (4). The PHA accumulation observed in the same anaerobic batch test is also shown in Fig. 6. The rate of PHA formation was found to be $6 \cdot 2 \times 10^{-3}$ C-mol (C-mol biomass) ${ }^{-1} \mathrm{~h}^{-1}$, where the composition of PHA produced was calculated as $12 \%$ $\mathrm{PHB}, 41 \% \mathrm{PHV}$ and $47 \% \mathrm{PH} 2 \mathrm{MV}$. The rate of $\mathrm{CO}_{2}$ formation was $2 \cdot 1 \times 10^{-3}$ C-mol (C-mol biomass) ${ }^{-1} \mathrm{~h}^{-1}$ from equation (2) using the TOGA data (not shown). The results obtained in this study are not well described by the proposed stoichiometry for anaerobic maintenance processes in equation (4). The reason for this is not well understood. Perhaps when the wastewater contains no VFA the maintenance process of GAOs is different to that when VFAs are present, or the maintenance of acetate-enriched GAOs (often dominated by Competibacter) may be different from that of these Alphaproteobacteria GAOs enriched on propionate. It should also be noted that equation (4) has not 


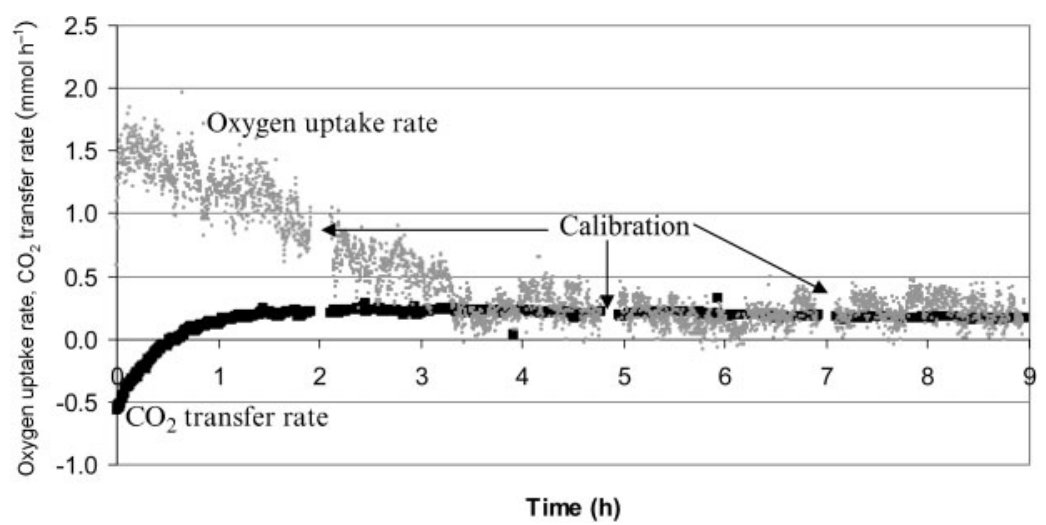

Fig. 5. Oxygen uptake rate and $\mathrm{CO}_{2}$ transfer rate from an extended aerobic period for determination of the energy required for aerobic cell maintenance. yet been validated experimentally, and may not describe the actual anaerobic maintenance process of GAOs.

The batch test performed with an extended aerobic period to estimate the aerobic maintenance process is shown in Fig. 5. After $4 \mathrm{~h}$ aeration, the rate of oxygen consumption $\left(m_{\mathrm{os}}\right)$ [in mol $\mathrm{O}_{2}$ (C-mol biomass $)^{-1} \mathrm{~h}^{-1}$ ] became relatively constant at a mean value of $0.22 \mathrm{mmol} \mathrm{h}^{-1}$, or $2 \cdot 7 \times 10^{-3} \mathrm{~mol}(\mathrm{C}$ mol biomass) $)^{-1} \mathrm{~h}^{-1}$. The oxygen uptake rate correlated well with the $\mathrm{CO}_{2}$ transfer rate during this time period (see Fig. 5), suggesting that almost all of the oxygen was converted to $\mathrm{CO}_{2}$, which is consistent with previous studies under maintenance conditions (Zeng et al., 2003b). The anaerobic and aerobic maintenance coefficients are compared with literature-reported values from previous studies with PAOs and GAOs in Table 4. It may be observed that the maintenance energy requirements are similar between PAOs and GAOs, while the $m^{\text {ATP }}$ values are slightly higher in both $\mathrm{PAO}$ and GAO cultures enriched with propionate as compared to acetate.

\section{Impact on the competition between PAOs and GAOs}

Recent studies have suggested that a propionate feed source is more beneficial for reliable EBPR performance than acetate (Chen et al., 2004; Oehmen et al., 2005a, 2006; Pijuan et al., 2004; Thomas et al., 2003), likely due to a reduced level of GAO activity. The metabolic activity of PAOs and GAOs fed with different carbon sources is compared in Table 4. The maximum specific VFA uptake rate $\left(q^{\max }\right)$ [in C-mol (C-mol biomass $)^{-1} \mathrm{~h}^{-1}$ ] and the aerobic biomass growth yield $\left(Y_{\text {growth }}\right)$ [in C-mol biomass growth (C-mol VFA uptake $)^{-1}$ ] are factors that may influence the competition between PAOs and GAOs in wastewater systems. The $q^{\max }$ and $Y_{\text {growth }}$ results from this study were very similar to most of the previously reported values for PAOs and GAOs, which does not clearly suggest that PAOs possess an advantage over GAOs when propionate is the carbon source. The reason for the observed advantage of PAOs in previous studies in which propionate was the carbon source is currently unknown.

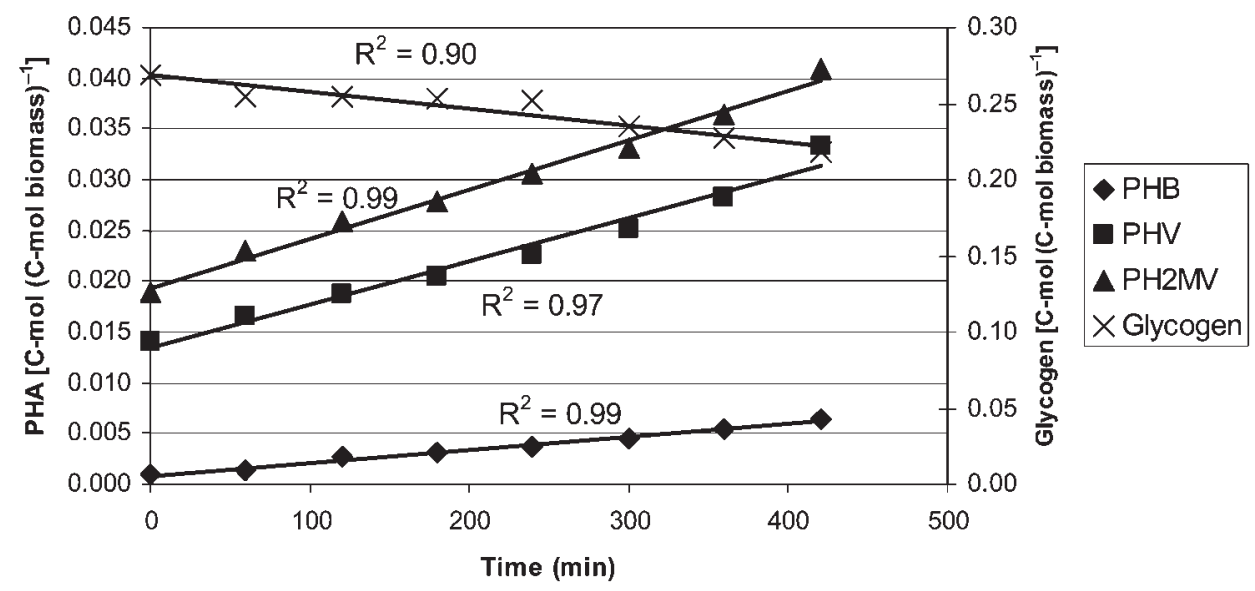

Fig. 6. The rate of glycogen hydrolysis and PHA accumulation observed during an anaerobic batch test without propionate addition. The energy required for anaerobic maintenance was calculated to be $3.5 \times 10^{-3}$ mol ATP $(\mathrm{C}-\mathrm{mol} \text { biomass })^{-1} \mathrm{~h}^{-1}$ from equation (4). 
Table 4. Comparison of VFA uptake rate, biomass growth yield and maintenance coefficients between this study and other PAO and GAO studies

NA, Not available.

\begin{tabular}{|c|c|c|c|c|c|c|}
\hline Carbon source & Organism & Publication & $q^{\max }$ & $Y_{\text {growth }}{ }^{*}$ & $m^{\mathrm{ATP}}$ & $m_{\mathrm{os}}{ }^{*}$ \\
\hline Propionate & PAO & Oehmen et al. (2005b) & $0 \cdot 18$ & $0 \cdot 35$ & $4 \cdot 2 \times 10^{-3}$ & $3 \cdot 8 \times 10^{-3}$ \\
\hline Acetate & GAO & Filipe et al. (2001a) & $0 \cdot 24$ & NA & $2 \cdot 1 \times 10^{-3}$ & NA \\
\hline Acetate & $\mathrm{PAO}$ & Smolders et al. (1995) & $0 \cdot 43$ & $0 \cdot 34$ & $2 \cdot 5 \times 10^{-3}$ & $4.5 \times 10^{-3}$ \\
\hline Acetate & $\mathrm{PAO}$ & Filipe et al. (2001b) & $0 \cdot 19$ & NA & $2 \cdot 0 \times 10^{-3}$ & NA \\
\hline
\end{tabular}

${ }^{\star} Y_{\text {growth }}$ and $m_{\mathrm{os}}$ were not presented previously in Oehmen et al. (2005b), although these parameters were obtained during that study.

Further investigation is required to assess the proliferation of these Alphaproteobacteria GAOs in EBPR plants as well as their ability to compete with PAOs in these systems.

The presence of these alphaproteobacteria GAOs in EBPR systems could have considerable ramifications for future investigations concerning the competition between PAOs and GAOs. Accumulibacter appears to be a dominant PAO in the presence of both acetate and propionate as carbon sources, and has been shown to have the capacity to switch between acetate and propionate uptake without the need for acclimation (Oehmen et al., 2005a; Pijuan et al., 2004). It is possible, however, that GAOs have a more specific preference for acetate or propionate. In one study, GAOs enriched with acetate as the sole carbon source (and dominated by Competibacter) were shown to be far less effective in propionate uptake, while GAOs enriched with propionate (dominated by Alphaproteobacteria) were shown to take up acetate at less than half the rate of propionate (Oehmen et al., 2005a). A carbon source preference exhibited by different groups of GAOs could perhaps be useful in minimizing the undesirable proliferation of GAOs in EBPR systems.

\section{Conclusions}

The anaerobic and aerobic metabolism of GAOs enriched with propionate as the sole carbon source has been described in this study. The main outcomes from this study can be summarized as follows.

The proposed metabolic model described well the anaerobic biochemical transformations by GAOs with propionate as the carbon source.

The biomass was highly enriched in Alphaproteobacteria with a tetrad morphotype. A fraction of these organisms were identified as D. vanus-related organisms. Furthermore, most Alphaproteobacteria in the biomass exhibited intracellular anaerobic-aerobic cycling of PHA.

The maximum specific VFA uptake rate and biomass growth yield of these Alphaproteobacteria GAOs were similar to values reported in the literature from PAO and GAO studies. It is unclear at present why these organisms seem to compete less effectively than PAOs when propionate is the carbon source, as has been suggested by previous studies.

The energy requirements for anaerobic and aerobic maintenance processes found in this study were similar to previously reported values for PAOs and GAOs.

Currently available oligonucleotide probes for GAO bound only $16 \%$ of the Bacteria in this system, whereas many more appeared to be cycling PHA, suggesting the presence of other GAOs. Further investigation into the phylogenetic diversity of GAOs, and their significance in EBPR systems, is recommended.

\section{ACKNOWLEDGEMENTS}

This project was funded by the Cooperative Research Centre for Waste Management and Pollution Control and the Environmental Biotechnology Cooperative Research Centre, centres formed by the Federal Government of Australia.

\section{REFERENCES}

Amann, R. I. (1995). In situ identification of microorganisms by whole cell hybridization with rRNA-targeted nucleic acid probes. In Molecular Microbial Ecology Manual, pp. 1-15. Edited by A. D. L. Akkermans, J. D. van Elsas \& F. J. de Bruijn. Dordrecht, Holland: Kluwer Academic Publications.

Amann, R. I., Binder, B. J., Olson, R. J., Chisholm, S. W., Devereux, R. \& Stahl, D. A. (1990). Combination of 16 S ribosomal-RNA-targeted oligonucleotide probes with flow-cytometry for analyzing mixed microbial-populations. Appl Environ Microbiol 56, 1919-1925.

American Public Health Association, American Water Works Association \& Water Pollution Control Federation (APHA, AWWA \& WPCF) (1995). Standard Methods for the Examination of Water and Wastewater, 19th edn. Baltimore: Port City Press.

Beer, M., Seviour, E. M., Kong, Y., Cunningham, M., Blackall, L. L. \& Seviour, R. J. (2002). Phylogeny of the filamentous bacterium Eikelboom Type 1851, and design and application of a 16S rRNA targeted oligonucleotide probe for its fluorescence in situ identification in activated sludge. FEMS Microbiol Lett 207, 179-183. 
Beer, M., Kong, Y. H. \& Seviour, R. J. (2004). Are some putative glycogen accumulating organisms (GAO) in anaerobic:aerobic activated sludge systems members of the alpha-Proteobacteria? Microbiology 150, 2267-2275.

Bond, P. L., Keller, J. \& Blackall, L. L. (1998). Characterisation of enhanced biological phosphorus removal activated sludges with dissimilar phosphorus removal performances. Water Sci Technol 37, 567-571.

Bouchez, T., Patureau, D., Dabert, P., Wagner, M., Delgenes, J. P. \& Moletta, R. (2000). Successful and unsuccessful bioaugmentation experiments monitored by fluorescent in situ hybridization. Water Sci Technol 41, 61-68.

Chen, Y., Randall, A. A. \& McCue, T. (2004). The efficiency of enhanced biological phosphorus removal from real wastewater affected by different ratios of acetic to propionic acid. Water Res 38, 27-36.

Crocetti, G. R., Hugenholtz, P., Bond, P. L., Schuler, A., Keller, J., Jenkins, D. \& Blackall, L. L. (2000). Identification of polyphosphateaccumulating organisms and design of $16 \mathrm{~S}$ rRNA-directed probes for their detection and quantitation. Appl Environ Microbiol 66, 11751182 .

Crocetti, G. R., Banfield, J. F., Keller, J., Bond, P. L. \& Blackall, L. L. (2002). Glycogen-accumulating organisms in laboratory-scale and full-scale wastewater treatment processes. Microbiology 148, 33533364.

Daims, H., Bruhl, A., Amann, R., Schleifer, K. H. \& Wagner, M. (1999). The domain-specific probe EUB338 is insufficient for the detection of all Bacteria: development and evaluation of a more comprehensive probe set. Syst Appl Microbiol 22, 434-444.

Filipe, C. D. M., Daigger, G. T. \& Grady, C. P. L. (2001a). A metabolic model for acetate uptake under anaerobic conditions by glycogen accumulating organisms: stoichiometry, kinetics, and the effect of pH. Biotechnol Bioeng 76, 17-31.

Filipe, C. D. M., Daigger, G. T. \& Grady, C. P. L. (2001b). Stoichiometry and kinetics of acetate uptake under anaerobic conditions by an enriched culture of phosphorus-accumulating organisms at different pHs. Biotechnol Bioeng 76, 32-43.

Gottschalk, G. (1986). Bacterial Metabolism, 2nd edn. New York: Springer.

Hesselmann, R. P. X., Werlen, C., Hahn, D., van der Meer, J. R. \& Zehnder, A. J. B. (1999). Enrichment, phylogenetic analysis and detection of a bacterium that performs enhanced biological phosphate removal in activated sludge. Syst Appl Microbiol 22, 454-465.

Kong, Y. H., Ong, S. L., Ng, W. J. \& Liu, W. T. (2002). Diversity and distribution of a deeply branched novel proteobacterial group found in anaerobic-aerobic activated sludge processes. Environ Microbiol 4, 753-757.

Levantesi, C., Serafim, L. S., Crocetti, G. R., Lemos, P. C., Rossetti, S., Blackall, L. L., Reis, M. A. M. \& Tandoi, V. (2002). Analysis of the microbial community structure and function of a laboratory scale enhanced biological phosphorus removal reactor. Environ Microbiol 4, 559-569.

Liu, W. T., Nielsen, A. T., Wu, J. H., Tsai, C. S., Matsuo, Y. \& Molin, S. (2001). In situ identification of polyphosphate- and polyhydroxyalkanoate-accumulating traits for microbial populations in a biological phosphorus removal process. Environ Microbiol 3, 110-122.

Manz, W., Amann, R., Ludwig, W., Wagner, M. \& Schleifer, K. H. (1992). Phylogenetic oligodeoxynucleotide probes for the major subclasses of proteobacteria - problems and solutions. Syst Appl Microbiol 15, 593-600.

Meyer, R. L., Saunders, A. M. \& Blackall, L. L. (2006). Putative glycogen-accumulating organisms belonging to Alphaproteobacteria identified through rRNA-based stable isotope probing. Microbiology 152, 419-429.

Neef, A. (1997). Anwendung der in situ Einzelzell-Identifizierung von Bakterien zur Populationsanalyse in komplexen mikrobiellen Biozönosen. PhD thesis, Technische Universität München.

Nielsen, A. T., Liu, W. T., Filipe, C., Grady, L., Molin, S. \& Stahl, D. A. (1999). Identification of a novel group of bacteria in sludge from a deteriorated biological phosphorus removal reactor. Appl Environ Microbiol 65, 1251-1258.

Oehmen, A., Yuan, Z., Blackall, L. L. \& Keller, J. (2004). Short-term effects of carbon source on the competition of polyphosphate accumulating organisms and glycogen accumulating organisms. Water Sci Technol 50, 139-144.

Oehmen, A., Yuan, Z. G., Blackall, L. L. \& Keller, J. (2005a). Comparison of acetate and propionate uptake by polyphosphate accumulating organisms and glycogen accumulating organisms. Biotechnol Bioeng 91, 162-168.

Oehmen, A., Zeng, R. J., Yuan, Z. G. \& Keller, J. (2005b). Anaerobic metabolism of propionate by polyphosphate-accumulating organisms in enhanced biological phosphorus removal systems. Biotechnol Bioeng 91, 43-53.

Oehmen, A., Saunders, A. M., Vives, M. T., Yuan, Z. \& Keller, J. (2006). Competition between polyphosphate and glycogen accumulating organisms in enhanced biological phosphorus removal systems with acetate and propionate as carbon sources. J Biotechnol 123, 2232.

Onda, S., Hiraishi, A., Matsuo, Y. \& Takii, S. (2002). Polyphasic approaches to the identification of predominant polyphosphateaccumulating organisms in a laboratory-scale anaerobic/aerobic activated sludge system. J Gen Appl Microbiol 48, 43-54.

Ostle, A. G. \& Holt, J. G. (1982). Nile blue A as a fluorescent stain for poly-beta-hydroxybutyrate. Appl Environ Microbiol 44, 238-241.

Pijuan, M., Saunders, A. M., Guisasola, A., Baeza, J. A., Casas, C. \& Blackall, L. L. (2004). Enhanced biological phosphorus removal in a sequencing batch reactor using propionate as the sole carbon source. Biotechnol Bioeng 85, 56-67.

Pratt, S., Yuan, Z., Gapes, D., Dorigo, M., Zeng, R. J. \& Keller, J. (2003). Development of a novel titration and off-gas analysis (TOGA) sensor for study of biological processes in wastewater treatment systems. Biotechnol Bioeng 81, 482-495.

Satoh, H., Mino, T. \& Matsuo, T. (1994). Deterioration of enhanced biological phosphorus removal by the domination of microorganisms without polyphosphate accumulation. Water Sci Technol 30, 203-211.

Saunders, A. M., Oehmen, A., Blackall, L. L., Yuan, Z. \& Keller, J. (2003). The effect of GAOs (glycogen accumulating organisms) on anaerobic carbon requirements in full-scale Australian EBPR (enhanced biological phosphorus removal) plants. Water Sci Technol 47, 37-43.

Seviour, R. J., Mino, T. \& Onuki, M. (2003). The microbiology of biological phosphorus removal in activated sludge systems. FEMS Microbiol Rev 27, 99-127.

Smolders, G. J. F., Vandermeij, J., Vanloosdrecht, M. C. M. \& Heijnen, J. J. (1994a). Stoichiometric model of the aerobic metabolism of the biological phosphorus removal process. Biotechnol Bioeng 44, 837-848.

Smolders, G. J. F., Vandermeij, J., Vanloosdrecht, M. C. M. \& Heijnen, J. J. (1994b). Model of the anaerobic metabolism of the biological phosphorus removal process - stoichiometry and $\mathrm{pH}$ influence. Biotechnol Bioeng 43, 461-470.

Smolders, G. J. F., Vandermeij, J., Vanloosdrecht, M. C. M. \& Heijnen, J. J. (1995). A structured metabolic model for anaerobic 
and aerobic stoichiometry and kinetics of the biological phosphorus removal process. Biotechnol Bioeng 47, 277-287.

Thomas, M., Wright, P., Blackall, L., Urbain, V. \& Keller, J. (2003). Optimisation of Noosa BNR plant to improve performance and reduce operating costs. Water Sci Technol 47, 141-148.

Voet, D. \& Voet, J. G. (1990). Biochemistry. New York: Wiley.

Whang, L. M. \& Park, J. K. (2002). Competition between polyphosphate- and glycogen-accumulating organisms in biological phosphorus removal systems - effect of temperature. Water Sci Technol 46, 191-194.

Wong, M. T., Tan, F. M., Ng, W. J. \& Liu, W. T. (2004). Identification and occurrence of tetrad-forming Alphaproteobacteria in anaerobicaerobic activated sludge processes. Microbiology 150, 3741-3748.
Zeng, R., Yuan, Z., van Loosdrecht, M. C. M. \& Keller, J. (2002). Proposed modifications to metabolic model for glycogen-accumulating organisms under anaerobic conditions. Biotechnol Bioeng 80, 277-279.

Zeng, R. J., Saunders, A. M., Yuan, Z., Blackall, L. L. \& Keller, J. (2003a). Identification and comparison of aerobic and denitrifying polyphosphate-accumulating organisms. Biotechnol Bioeng 83, 140-148.

Zeng, R. J., van Loosdrecht, M. C. M., Yuan, Z. G. \& Keller, J. (2003b). Metabolic model for glycogen-accumulating organisms in anaerobic/ aerobic activated sludge systems. Biotechnol Bioeng 81, 92-105.

Zilles, J. L., Peccia, J. \& Noguera, D. R. (2002). Microbiology of enhanced biological phosphorus removal in aerated-anoxic orbal processes. Water Environ Res 74, 428-436. 